\title{
Analysis on the status quo and countermeasures of human resource management in energy enterprises under the new situation
}

\author{
Jianguo Liu*, Bixiang Zhu
}

School of Economics \& management, Nanjing University of Science \& Technology, Nanjing, China ${ }^{*}$ Corresponding author: 1554721597@qq.com

\begin{abstract}
With the arrival of the new era, China's industrial structure has entered strategic transformation, and the development of energy enterprises is faced with many challenges. In order to help the sustainable development of enterprises and improve the core competitiveness, we must spare no effort to exert the role of human resource management.At present, there are many problems in human resource management of energy companies.In this paper, the current situation and existing problems of human resource management in energy enterprises are analyzed and discussed, and then solutions to the corresponding problems are obtained. This paper discusses the key points of human resource management from the aspects of staff recruitment, training and performance appraisal.
\end{abstract}

Keywords: energy enterprise; human resource management; status quo and countermeasures.

\section{Introduction}

At present, the international and domestic economic situation is becoming more and more complex, with more and more uncertain factors, and the domestic and foreign economic environment competition of energy enterprises is becoming increasingly fierce. Figure 1 shows the energy production structure from 2010 to 2019 , as shown below. Faced with increasingly severe challenges in economic growth mode transformation, industrial structure upgrading, natural environment and other aspects, in order to truly ensure the sustained and stable economic growth of energy enterprises, it is necessary to adjust the corresponding structure in time and improve human resource management strategies.

As the core and foundation of competition in the era of knowledge economy, human resources need to explore effective management measures to improve the comprehensive quality of talents and work level. As to realize strategic transformation and sustainable development of energy enterprises, the key lies in people. Enterprises should attach great importance to the status and role of talents in development, and properly control each important link of human resource management, so as to help enterprises maximize the use of resources, so that human resource management can really do a good job in organizing and supporting talents for the development of enterprises, then ensure the internationalization, marketization and standardized development of enterprises.[1]

With the continuous introduction of China's economic policies, energy enterprises facing the internal and external environment which is undergoing profound changes. As an important pillar of the national economy, energy enterprises must play a leading role and vigorously promote the reform of enterprise human resource management. The author analyzes and discusses the current situation and existing problems of human resource management in energy enterprises, and then comes up with corresponding solutions to boost the development of energy enterprises in the difficult environment. 


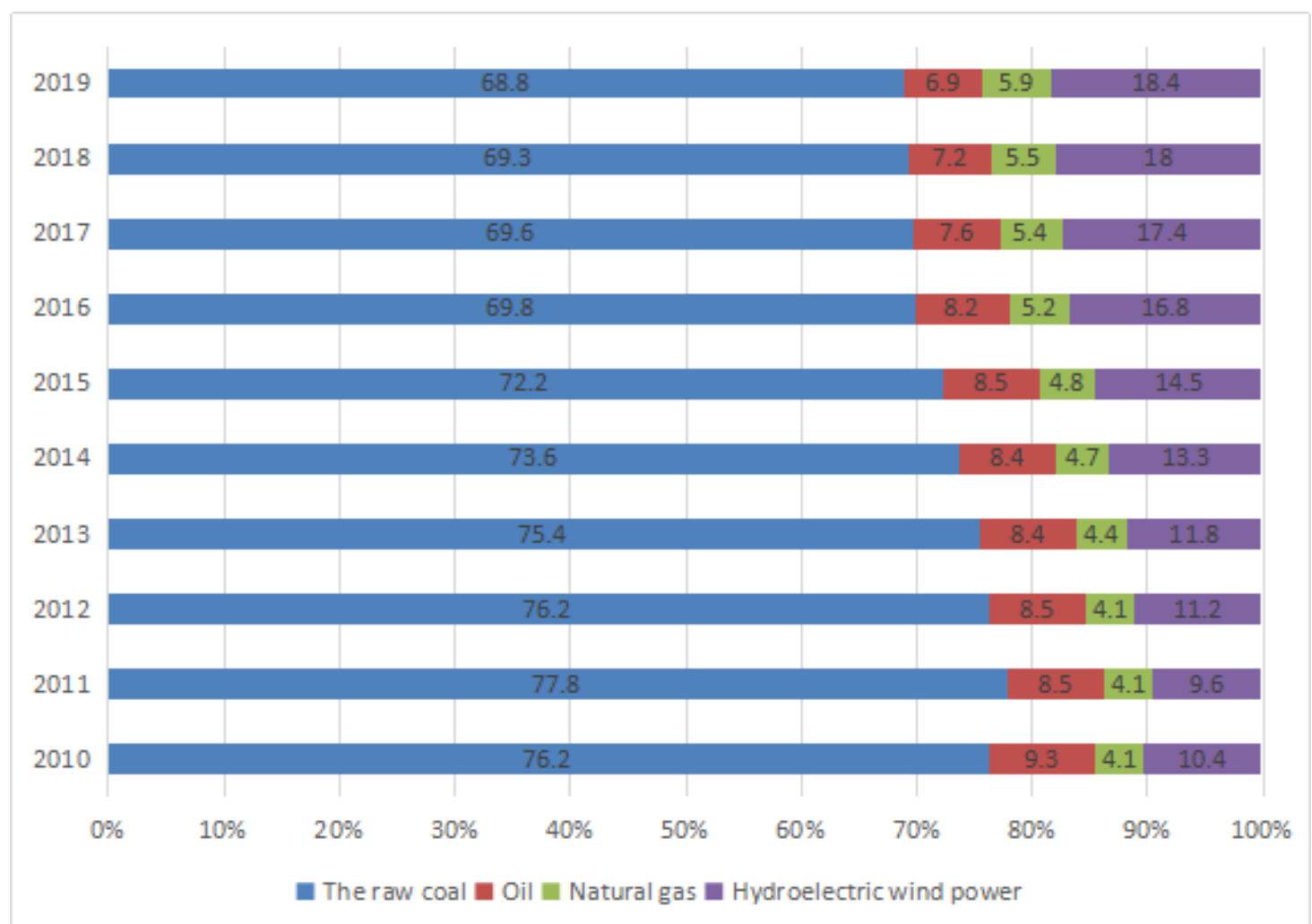

Figure 1. Energy production structure (\%) from 2010 to 2019 (data source: calculated from the National Bureau of Statistics)

\section{An overview of human resource management}

The concept of human resource was put forward by Peter F. Drucker from the United States, who clearly pointed out that human resource is a kind of special and specific resource. The encouragement and development of human resource can bring great value to the development of enterprises. However, domestic scholars' research on human resources puts forward that human resource management is a process of developing, planning, implementing, using and governing human resources. The author believes that human resource management should start from the personal development and organizational planning of human resources, establish a sound management mechanism, achieve the effective development of human resources, and optimize the management process, methods and technologies.[2]

Modern human resource management is a part of the business strategy, with "people" as the core, emphasizing a dynamic, psychological, consciousness of the adjustment and development, the fundamental starting point of management is "people-oriented". People, is an important resource in enterprise management, is also the first resource. To be specific, it is a kind of management behavior that enterprises improve work efficiency through a series of means such as job analysis, human resource planning, employee recruitment and selection, performance evaluation, salary management, employee motivation, talent training and development, and finally achieve the development goals of enterprises.

Modern human resource management regards people as a kind of "resource", pays attention to output and development, and achieves the harmony between "people" and "things", "people" and "people". Such harmony will bring the improvement of work efficiency, so as to achieve the ultimate goal. Japanese entrepreneur Konosuke Matsushita famously said, "A company's best asset is its people." Therefore, the connotation of modern human resource management determines that "people" is the cornerstone to enhance the core competitiveness of enterprises. 


\section{The status quo of human resource management in energy enterprises under the new situation}

First of all, most employees in the energy industry belong to the old power enterprises, and the employees usually have solidified ideas and serious habitual thinking. Secondly, most of the professionals are non-professional graduates, whose professional quality needs to be strengthened, especially the lack of technical management personnel with specific theories and practical experience. Then, the project environment of energy enterprises is harsh, the task is heavy, and the business training work cannot be carried out in a timely and effective manner, which makes the employees of the enterprises, especially the new employees, confused and abandoned, resulting in the situation of too much people but lack of human resources. Finally, some energy companies do not popularize the performance appraisal system, or even do not adopt the performance appraisal system or the appraisal method is too single. Therefore, it is urgent to change the concept of human resource management, break through the shackled thinking, promote the reform and optimization of human resource management, and continuously improve the ability of the overall utilization of human resources in enterprises.[3]

\section{Problems faced by human resource management in energy enterprises in the new era}

The human resource management system of modern enterprises has broken the shackles of the traditional human resource management system in the aspect of personnel management and optimized the management strategies of enterprises. However, in the development process of energy enterprises in the new era, there are still many problems in the human resource management system. The following is a brief analysis of the existing problems in the human resource management of energy enterprises.

\subsection{The lack of professional talents, the overall quality of staff is poor, the recruitment method is single and the system is not perfect}

At present, there is a big difference between technical and non-technical personnel in energy companies, the overall quality of employees is uneven, and highly educated talents are in short supply.[4] Energy companies do not make a reasonable forecast of the company's job demand and human resource supply before recruiting technical personnel, so they blindly recruit technical personnel. In addition, the recruitment method is relatively simple. Energy companies generally recruit talents through two ways: internal recruitment and external recruitment.

The so-called "internal recruitment" refers to the internal transfer and promotion of employees in energy companies. Although they have a better understanding of the actual situation of the company, their management skills are poor and they are obviously unable to cope with the actual management work." External recruitment" is the recruitment of talent through job fairs, usually including campus recruitment and internal staff recommendation. For the current development situation of energy companies, campus recruitment is the best way to recruit talents, which can maximize the recruitment of highly educated and high-quality talents corresponding to their major and corresponding posts. However, this recruitment method is not universal. In addition, in the process of recruitment and selection, its recruitment mode is relatively fixed, and the organizational recruiters have not prepared for the problems that may occur on the recruitment site. Table 1 shows the recruitment and entry status of X Company in one month (October is the autumn recruiting season). 
Table 1. The recruitment and entry status of X Company in October.

\begin{tabular}{cccc}
\hline Recruitment channels & Number of resumes & The number of inductions & Conversion rate \\
\hline Internal recommend & 10 & 4 & $40 \%$ \\
Campus recruitment & 34 & 20 & $59 \%$ \\
\hline
\end{tabular}

\subsection{Staff training is lack of professionalism and pertinence}

In the development process of energy companies, the training of internal employees is a long-term, scientific and systematic professional project, and certain procedures need to be followed in the training process of energy companies. However, in the current employee training process of energy companies, they over-rely on the existing training system and fail to teach employees in accordance with their own potential and characteristics. The training content is not targeted, the cultivation of corporate culture is not enough attention and the training methods are not diversified. Under this mode, the training results cannot keep up with the development needs of production and operation, and cannot promote the technological innovation and institutional innovation of energy companies.[4] Secondly, energy companies invest a lot of human resource, material resources and financial resources in training new employees and front-line employees, but ignore the training needs of management. The neglect of management personnel training results in the lack of effective improvement of the management ability of energy companies, which reduces the effective integration degree of the management ability and corporate culture of energy companies.

\subsection{Corporate performance evaluation is not systematic}

The traditional human resource management system of energy companies is no longer in line with today's development. Therefore, many energy companies have adopted the performance appraisal system to evaluate the work of employees through the performance management of their employees, so as to measure the operating level of energy companies. So far, however, the performance appraisal system does not have a systematic operation process and systematic performance management, so some energy companies have not popularized the performance appraisal system, or even adopted the performance appraisal system. In energy companies that have adopted performance appraisal system, employees do not have a deep understanding of how to conduct performance appraisal and how to use performance appraisal system to evaluate employees' ability within the company. [4] There are many problems, manifested in three aspects, one is not to the staff's personal situation to do a detailed analysis, and then the assessment indicators cannot meet the specific needs; Second, the incentive mechanism has not been established, the salary system is unreasonable, and the staff lacks enthusiasm for work; Third, the staff is busy, involving a wide range of content, performance appraisal content is not comprehensive enough.

\section{Reform and optimization of HRM strategy of energy enterprises in the new situation}

\subsection{Improve the overall quality of staff and improve the recruitment work and recruitment system}

We will focus on the absorption of highly educated, high-quality management personnel and professional and technical personnel, and make up for the personnel of relevant posts according to the actual situation. We will actively introduce complex professionals, optimize the internal resource allocation of the energy company, and improve the overall quality and work efficiency of the staff. According to the changes of the energy market, rationally allocate the recruitment demand of the energy company, and strive to achieve the matching of staff and posts. Fully improve the specific process in advance and in the process of recruitment, make the recruitment process concrete and practical, and carry out a series of processes such as personnel demand summary and report, 
examination and approval, preliminary formulation, and talent recruitment according to the specific system of the energy company. More importantly, in the field of talent recruitment, the organization and recruitment personnel should make appropriate adjustments according to the actual situation and do a good job in the follow-up work after talent recruitment, so as to optimize the personnel structure in an all-round way.

\subsection{Build a diversified training system}

Emphasis should be paid to the cultivation of versatile talents, and a multi-directional, multi-level and multi-type talent training system should be established. Increase training on new processes, new technologies and new ideas to help enterprises adapt to the new competitive environment. Accurately grasp the characteristics of the operating personnel team, professional and technical personnel team and management team, classify each professional and stratify according to the positions.[5]Develop training contents for all kinds of personnel from the primary level to the core level, track the career of each employee, and adjust the training plan at any time according to the growth status of employees. The mentoring system should be carried out purposefully and in a planned way, so as to cultivate talents with high professional quality, professional ethics and good work style and spirit.

\subsection{Establish a scientific performance appraisal system}

The human resource management department should establish a sound evaluation mechanism according to the existing personnel composition of the enterprise and the interests, characteristics and specialties of each staff member. At the same time, according to the difference of posts, different assessment indicators should be formulated. Assessment rules should be formulated according to the educational background, professional title and development direction of the staff, and an assessment system of key performance indicators should be established. Decompose the company's annual operation and management objectives, refine them and implement them to each functional department, and take them as the assessment indicators of the department. In addition, the corresponding reward and punishment mechanism can be formulated to achieve strict management, and then improve the evaluation effect of managers. It is also necessary to improve the salary system, achieve the organic combination of spiritual rewards and material rewards, and take this as an important basis for promotion in the future, while mobilizing the enthusiasm of staff, strengthen staff's attention to the performance evaluation. Finally, the performance appraisal results of different periods should be sent to personal files and individual hands simultaneously, so that the staff can correctly understand their own strengths and weaknesses, and then provide sufficient data support for the next improvement.[6]Effective performance communication in the setting stage can ensure that the goals set are reasonable enough, and the performance executors are more likely to agree with the goals.

\section{Conclusion}

To sum up, with the continuous development of market economy, energy companies should actively respond to the specific requirements of the national reform, innovate the management mode and system, constantly adjust the corresponding human resource management strategies, and at the same time strengthen the emphasis on human resource management. Energy companies must fully understand the current situation, start from their own problems, and take corresponding measures to properly deal with the problems existing in the human resource management system. Through continuous exploration, we will improve the recruitment work and recruitment system, build a diversified training system, establish a scientific performance evaluation system, reform and optimize the level of human resources management, and promote the sustainable development of the enterprise. 


\section{References}

[1] Du NI. Analysis of Human Resource Management in Energy Enterprises under the New Situation [J]. Coal Economic Research, 2016, 36 (08): 49 - 52.

[2] Yin Mingwen. Problems and Countermeasures of Human Resource Management in Energy Companies [J]. Taxation, 2019, 13 (11): 249+251.

[3] Feng Yansong. Strategic Human Resource Management of New Energy Development and Construction Enterprises [J]. Shanxi Architecture, 2013, 39 (34): 242 - 243.

[4] Xing Jing. Human resource management problems and countermeasures of energy companies [J]. Economic and Trade Practice, 2017 (06): 218.

[5] Du Yong. Analysis of Human Resource Management in Energy Enterprises under the New Situation [J]. Labor Security World, 2020 (09): 2.

[6] Li Xiaosu. Discussion on Countermeasures of Strengthening Human Resource Management in Power Supply Enterprises [J]. Rural Electrical Engineering, 2013, 21 (10): 8. 